\title{
ANALISIS KELAYAKAN FINANSIAL SISTEM PENGELOLAAN SAMPAH DI DESA PENEBEL KABUPATEN TABANAN
}

\author{
DEWA AYU PUTU ADHIYA GARINI PUTRI ${ }^{1)}$, ADIE WAHYUDI OKTAVIA GAMA ${ }^{2)}$ \\ ${ }^{1}$ Jurusan Teknik Sipil Fakultas Teknik dan Informatika Universitas Pendidikan Nasional \\ Jalan Bedugul No. 39, Sidakarya, Denpasar-Bali \\ ${ }^{2}$ JurusanTeknologi Informasi Fakultas Teknik dan Informatika Universitas Pendidikan Nasional \\ Jalan Bedugul No. 39, Sidakarya, Denpasar-Bali \\ e-mail: ${ }^{1)}$ adhiyagariniputri@undiknas.ac.id, ${ }^{2)}$ adiewahyudi@undiknas.ac.id
}

\begin{abstract}
ABSTRAK
Sampah saat ini menjadi isu utama dalam upaya pembangunan paradigma pariwisata saat ini menuju pariwisata yang berkelanjutan. Manajemen pengelolaan sampah tentunya diperlukan untuk menjaga lingkungan menjadi tetap bersih dan asri. Pengelolaan sampah pun tidak hanya menjangkau wilayah perkotaan, namun juga mencakup wilayah perdesaan. Salah satunya pada wilayah Desa Penebel, Kecamatan Penebel Kabupaten Tabanan. Desa Penebel saat ini sedang melakukan upaya pengelolaan sampah secara mandiri ditingkat desa. Wilayah Desa Penebe saat inI terdiri dari 9 banjar dinas yang memiliki jumlah penduduk sebesar 4.175 jiwa. Salah satu upaya telah dilakukan adalah dengan merancang pembangunan Tempat Pengelolan Sampah Terpadu (TPST) 3R di lingkungan Desa Penebel. Studi yang dilakukan adalah analisis kelayakan financial dari system pengelolaan sampah yang terdapat pada Desa Penebel. Berdasarkan hasil studi kelayakan finansial pada model pengelolaan sampah di Desa Penebel diketahui nilai NPV adalah sebesar Rp. 694,166,994,426,-> 0 dan besar nilai BCR adalah 2,58 >1. Kedua nilai NPV dan BCR lebih besar dari syarat yang ditentukan, sehingga investasi dinyatakan layak NPV $>0$ dan BCR $>1$.
\end{abstract}

Kata kunci: pengelolaan sampah, kelayakan finansial dan TPST

\begin{abstract}
Waste is currently a major issue in the development of the current tourism paradigm towards sustainable tourism. Waste management is certainly needed to keep the environment clean and beautiful. Waste management does not only reach urban areas, but also includes rural areas. One of them is in the area of Penebel Village, Penebel District, Tabanan Regency. Penebel Village is currently conducting an independent waste management effort at the village level. The Penebel Village area currently consists of 9 banjar dinas which have a total population of 4,175 people. One effort has been made is to design a 3R Integrated Waste Management Site (TPST) within the Penebel Village. The study conducted is a financial feasibility analysis of the waste management system found in Penebel Village. Based on the results of a financial feasibility study on the waste management model in Penebel Village, the NPV value is Rp. 694,166,994,426, -> 0 and the value of BCR is 2.58>1. Both NPV and BCR values are greater than the specified conditions, so the investment is declared NPV>0 and BCR>1.
\end{abstract}

Keywords: waste management; financial feasibility; TPST

\section{PENDAHULUAN}

\section{Latar Belakang}

Kota Tabanan merupakan salah satu kota yang termasuk dalam kawasan metropolitan di Provinsi Bali. Hal ini tertuang dalam Peraturan Presiden No. 45 Tahun 2011 tentang Rencana Tata Ruang Kawasan Perkotaan Denpasar, Badung, Gianyar dan Tabanan. Berdasarkan data yang dihimpun pada Kementerian Pekerjaan Umum dan Perumahaan Rakyat tentang Pusat Pengembangan Kawasan Perkotaan, jumlah penduduk di kawasan metropolitan Sarbagita mencapai 2.388.680 jiwa. Data menyebutkan hampir 22\% dari total jumlah penduduk dikawasan Metropolitan Sarbagita menduduki Kabupaten Tabanan. Semakin tinggi jumlah pertumbuhan penduduk pada suatu daerah tentuny aakan berpengaruh pada pola kehidupan masyarakat dan lingkungan sekelilingnya. Salah satu permasalahan yang sangat dekat dengan pola hidup masyarakat dan lingkungan adalah sampah. Sampah saat ini menjadi isu utama dalam upaya pembangunan paradigma pariwisata saat ini menuju pariwisata yang berkelanjutan. Manajemen pengelolaan sampah 
tentunya diperlukan untuk menjaga lingkungan menjadi tetap bersih dan asri. Dalam Peraturan Gubernur Provinsi Bali Nomor 47 Tahun 2019 mengenai Pengelolaan Sampah Berbasis Sumber, pengelolaan sampah tidak hanya menjadi tugas pemerintah terkait tetapi masyarakat turut berperan serta aktif untuk ikut melakukan pengelolaan sampah hingga level rumah tangga.

Pengelolaan sampah pun tidak hanya menjangkau wilayah perkotaan, namun juga mencakup wilayah perdesaan.Peningkatan kualitas hidup masyarakat perdesaan membuat isu sampah menjadi semakin global. Selain itu kemajuan teknologi saat ini tentunya berimbas pada meningkatnya pola konsumsi masyarakat, khususnya wilayah perdesaan. Saat ini pemerintah berupaya meningkatkan peran serta masyarakat dalam kegiatan pengelolaan sampah di lingkungan Desa. Peran serta masyarakat tentunya menjadi sangat penting mengingat jumlah timbulan sampah yang paling tinggi berasal dari lingkungan rumah tangga.

Desa Penebel saat ini sedang melakukan upaya pengelolaan sampah secara mandiri ditingkat desa. Wilayah desa Penebel saat ini terdiri dari 9 banjar dinas yang memiliki jumlah penduduk sebesar 4.175 jiwa. Salah satu upaya telah dilakukan adalahd engan merancang pembangunanT empat Pengelolan Sampah Terpadu (TPST) 3R dilingkungand esa Penebel. Dengan perencanaan pembangunan TPST 3R diharapkan akan meminimalisir dampak sampah bagi lingkungan di Desa Penebel.

\section{Tujuan dan Manfaat Penelitian}

Penelitian ini bertujuan untuk memberikan simulasi model pengelolaan sampah dengan menghitung nilai investasi dari pengelolaan sampah tersebut. Manfaat yang diharapakan adalah Pemerintah Desa Penebel mendapatkan saran mengenai model investasi yang akan digunakan pada pengelolaan sampah di Desa Penebel.

\section{METODE PENELITIAN}

\section{Tahapan Penelitian}

Penelitian ini diawali dengan studi pendahuluan, studi literatur, dan menentukan rencana lokasi penelitian. Dalam hal ini lokasi penelitian ditentukan di Desa Penebel, Kecamatan Penebel Kabupaten Tabanan. Kemudian dilanjutkan dengan pengumpulan data primer dan sekunder. Studi yang dilakukan adalah analisis kelayakan finansial dari sistem pengelolaan sampah yang terdapat pada Desa Penebel. Berdasarkan hasil analisis, kemudian dilanjutkan dengan kesimpulan dan saran.

\section{Metode Pengumpulan Data}

Pengumpulan data primer dilakukan dengan melakukan pengukuran jarak rumah penduduk terjauh dari TPST. Sedangkan untuk data sekunder dapat dilihat berdasarkan data-data historis dari desa seperti jumlah penduduk atau pun jumlah kepala keluarga dalam suatu desa, jumlah produksi sampah harian, biaya investasi yang diperlukan dalam membangun TPST.

\section{Model Pengelolaan Sampah}

Model pengelolan sampah di Desa Penebel menggunakan konsep 3R yaitu reuse, reduce dan recycle. Sampah dari masing-masing rumah tangga dipilah terlebih dahulu. Untuk sampah organic dikumpulkan kemudian dimasukan ke dalam lubang resapan (biopori). Sampah yang dimasukan kedalam lubang biopori adalah sampah organic berupa sisa makanan ataupun sampah organic basah. Untuk sampah jenis lainnya (sampah organic kering, non organik dan residu) kemudian dikumpulkan,dipilah dan ditempatkan pada tempat tertentu. Lubang resapan ini telaht erdapat pada masing-masing rumahtangga.Kemudian sampahakan diangkut oleh petugas dan diantarkan menuju TPST. Pada TPST, sampah dipilah berdasarkan jenis sampah. Sampah organik dikumpulkan dan diproses pada mesin pencacah, kemudian setelah menjadi material yang lebih kecil dilakukan proses composting. Sedangkan untuk tipe sampah non organik juga dikumpulkan dan dimasukan ke dalam mesin pencacah. Tujuan dari pengelolaan sampah ini adalah untuk megurangi volume sampah yang dihasilkan rumah tangga, sehingga hal ini juga dapat mengurangi timbulan sampah tersebut.

\section{Analisis Kelayakan Finansial}

Untuk mengetahui potensi keuntungan yang didapatkan oleh pihak pengelola digunakan analisis kelayakan finansial, dengan metode Net Present Value, Benefit Cost Ratio, Internal Rate of Return. Selain itu 
dilakukan pula analisis mengenai payback period untuk mengetahui lama waktu yang dibutuhkan agar total manfaat dan pengeluaran untuk mencapai posisi balik modal atau potensi break event point.

Pada akhir penelitian didapatkan kesimpulan dan saran yang dapat berguna untuk pengembangan model pengelolaan sampah berikutnya. Biaya yang diperhitungkan dalam analisis kelayakan finansial ini adalah biaya angkut personel pengangkut, biaya pengangkutan, biaya composting dan biaya operasional.

\section{Kondisi Eksisting Sistem Pengelolaan Sampah di Desa Penebel}

Saat ini Pengelolaan sampah di Desa Penebel dilakukan secara swadaya masyarakat. Masyarakat sedang melakukan upaya untuk mengurangi timbukan sampah plastik. Pemerintah desa dan masyarakat melakukan inisiasi melalui kegiata benrsih pada selokan-selokan dan kegiatan 1000 biopori pada lingkup rumah tangga. Lokasi pengelolaan sampah yang terletak di Desa Penebel adalah seluas 400 meter persegi.

\section{HASIL DAN PEMBAHASAN}

\section{Gambaran Umum Model Pengelolaan Sampah}

Analisis kelayakan finansial ini membahas mengenai sifat ekonomis dan teknis yang berkaitan dengan analisis biaya. Waktu pelaksanaan konstruksi dilakukan secara bertahap pada tahun 2018. Biaya investasi diasumsikan berasal dari subsidi dana operasional desa dalam jangka waktu 3 tahun. Untuk tarir retribusi yang dipergunakan adalah tarif retribusi yang berasalandari sampah domestic rumah tangga. Biaya yang diperhitungkan dalam analisis investasi ini adalah biaya operasional pengelolaan seperti biaya personel pengangkut, biaya pembelian alat, biaya pembuatan kompos. Sedangkan biaya investasi berupa lokasi lahan dan bangunan di asumsikan adalah hasil subsidi pemerintah.

Indikator yang digunakan dalam melakukana nalisis kelayakan finansial ini adalah Net Present Value (NPV), dan Finansial Rate Of Return (IRR). Nilai IRR dihitung dengan menganggap NPV sama dengan nol.

\section{Pendapatan Retribusidari Sampah Domestik}

Berdasarkan hasil dari retribusi sampah diasumsikan untuk setiap rumah tangga membayar retribusi sampah per bulan adalah sebesar Rp. 10.000,-. Pendapatan retibusi dihitung dengan mengalikan prediksi jumlah peningkatan rumah tangga dikalikan dengan hargar etribusi sampah pertahun. Indikator pertumbuhan penduduk digunakan berdasarkan data presentase laju jumlah pertumbuhan penduduk dari data Badan Pusat Statistik sebesar 17\%. Hasil analisis mengenai pendapatan untuk sampah rumah tangga dijelaskan pada Tabel 1 .

Tabel 1. Hasil Prediksi Pendapatan Retribusi Sampah

\begin{tabular}{|c|c|c|c|}
\hline Tahun & $\begin{array}{c}\text { Jumlah Rumah } \\
\text { Tangga } \\
\text { (jiwa) }\end{array}$ & $\begin{array}{c}\text { Harga } \\
\text { Restribusi } \\
\text { (Rp) }\end{array}$ & $\begin{array}{c}\text { Pendapatan } \\
\text { Restribusi } \\
\text { (Rp) }\end{array}$ \\
\hline 2020 & 4,175 & 10,000 & $501,000,000$ \\
2021 & 4,885 & 10,000 & $586,170,000$ \\
2022 & 5,715 & 10,000 & $685,818,900$ \\
2023 & 6,687 & 10,000 & $802,408,113$ \\
2024 & 7,823 & 10,000 & $938,817,492$ \\
2025 & 9,153 & 10,000 & $1,098,416,466$ \\
2026 & 10,710 & 10,000 & $1,285,147,265$ \\
2027 & 12,530 & 10,000 & $1,503,622,300$ \\
2028 & 14,660 & 10,000 & $1,759,238,091$ \\
2029 & 17,153 & 10,000 & $2,058,308,567$ \\
2030 & 20,069 & 10,000 & $2,408,221,023$ \\
2031 & 23,480 & 10,000 & $2,817,618,597$ \\
2032 & 27,472 & 10,000 & $3,296,613,758$ \\
2033 & 32,142 & 10,000 & $3,857,038,097$ \\
2034 & 37,606 & 10,000 & $4,512,734,574$ \\
2035 & 43,999 & 10,000 & $5,279,899,451$ \\
2036 & 51,479 & 10,000 & $6,177,482,358$ \\
2037 & 60,230 & 10,000 & $7,227,654,359$ \\
2038 & 70,470 & 10,000 & $8,456,355,600$ \\
2039 & 82,449 & 10,000 & $9,893,936,052$ \\
\hline
\end{tabular}

Sumber : Hasil Analisis Data, 2020. 


\section{Biaya Investasi dan Pengelolaan}

Biaya investasi dan pengelolaan dibagi menjadi 2 yaitu biaya investasi Gedung dan biaya operasional.

\section{Biaya Investasi}

Biaya investasi yang dimaksud adalah biaya dari pembangunan area TPST. Pembangunan area TPST dibangun pada area seluas $400 \mathrm{~m} 2$. Biaya investasi ini akan diperhitungkan pada saat perhitungan kelayakan financial dilihat dari pihak operator atau pihak pengelola TPST. Biaya investasi terdiri dari 2 yaitu investasi pembangunan dan investasi peralatan operasional yang dijelaskan pada Tabel 2.

Tabel 2. Estimasi Biaya Investasi Gedung dan Peralatan TPST

\begin{tabular}{|c|c|c|c|}
\hline A.Biaya Pembangunan & Luas Areal $\left(\mathrm{m}^{2}\right)$ & $\begin{array}{c}\text { Estimasi Biaya } \\
\text { Pekerjaan }\left(\mathrm{Rp} / \mathrm{m}^{2}\right)\end{array}$ & $\begin{array}{l}\text { Total Biaya } \\
\text { (Rp) }\end{array}$ \\
\hline Pembersihan Area & 200 & 1.500 .000 & 1.500 .000 \\
\hline Pembangunan Area Pemilahan & 200 & 300.000 & 60.000 .000 \\
\hline Pembangunan Area Composting & 200 & 500.000 & 100.000 .000 \\
\hline Peralatan Area TPST & 230 & 75.000 & 17.250 .000 \\
\hline \multicolumn{4}{|l|}{ B. Biaya Peralatan } \\
\hline Jenis Pembelian & Jumlah Buah & Harga /satuan & Total Biaya (Rp) \\
\hline Pembelian Alat Pencacah & 1 & 25.000 .000 & 25.000 .000 \\
\hline Pembelian Alat Composting & 1 & 25000.000 & 25.000 .000 \\
\hline Pembelian Kendaraan Pengangkut & 1 & 20.800 .000 & 20.800 .000 \\
\hline \multicolumn{3}{|l|}{ Total Biaya Investasi } & 249.550 .000 \\
\hline
\end{tabular}

Sumber : Hasil Analisis Data, 2020

\section{Biaya Pengelolaan}

Biaya pemeliharaan dan pengelolaan Gedung terdiri dari biaya gaji personil dan biayalangsung seperti biaya bahan bakar, biaya listrik dan biaya pemeliharaan mesin. Tabel 3 dan 4 akan menjelaskan estimasi biaya pengelolaan TPST selama setahun.

Tabel 3. Estimasi Biaya Pengelolaan TPST

\begin{tabular}{|c|l|c|c|c|}
\hline \multicolumn{5}{|l|}{ A. Biaya Personil } \\
\hline No. & \multicolumn{1}{|c|}{ Keterangan } & Jumlah (Orang) & Biaya (Rp) & Total Biaya (Rp) \\
1 & Petugas Pengangkut Sampah & 2 & 2.625 .216 & 5.250 .432 \\
2 & PetugasAdmnistrasi & 1 & 2.625 .216 & 2.625 .216 \\
3 & Petugas Jaga TPS \&PemilahSampah & 2 & 2.625 .216 & 5.250 .432 \\
\hline \multicolumn{4}{|l}{ Total Biaya Personil per bulan } \\
Total BiayaPersonilselamasetahun
\end{tabular}

Sumber : Hasil Analisis Data, 2020

Tabel 4. Estimasi Biaya Pengelolaan TPST (2)

\begin{tabular}{|c|c|c|c|c|}
\hline \multicolumn{5}{|c|}{ B. Biaya Langsung } \\
\hline No & Keterangan & Jumlah (bulan) & Biaya (Rp) & Total Biaya (Rp) \\
\hline 1 & Biaya Bahan Bakar Motor & \begin{tabular}{|c|}
1 \\
\end{tabular} & 1.500 .000 & 1.500 .000 \\
\hline 2 & Biaya Bahan Bakar Mesin Pencacah & 1 & 500.000 & 500.000 \\
\hline 3 & Biaya Pemeliharaan Mesin dan TPS 3R & 1 & 500.000 & 500.000 \\
\hline 4 & Biaya Listrik & 1 & 500.000 & 500.000 \\
\hline 5 & Biaya ATK & 1 & 200.000 & 200.000 \\
\hline \multicolumn{2}{|c|}{ Total Biaya Personil per bulan } & & & 3.200 .000 \\
\hline \multicolumn{2}{|c|}{ Total Biaya Personil selama setahun } & & & 38.400 .000 \\
\hline
\end{tabular}

Sumber : Hasil Analisis Data, 2020 


\section{Analisis NPV, BCR dan IRR}

Parameter yang ditinjau yaitu initial cost, biaya manajemen dan operasional serta pendapatan.

Investasi (I) = Rp.249,550,000,-

Annual Cost (Ac) $\quad=$ Rp. 195.912.960,-

Biaya Annual cost merupakanbiayapertahun dan diprediksimeningkatsetiaptahunsebesar $15 \%$.

Umurinvestasi $(\mathrm{n}) \quad=20$ tahun

I $=20 \%$

Adapun persyaratan dalam mengkaji kelayakan analisis financial adalah sebagai berikut:

\section{Net Present Value (NPV)}

NPV $=$ Pendapatan - Investasi - Pengeluaran

Kalau NPV $<0$ maka investasi itu tidak layak

Kalau NPV > 0 maka investasi itu layak

\section{Benefit Cost Ratio (BCR)}

PWB $=$ Pendapatan

$\mathrm{PWC}=$ Investasi + Pengeluaran

$\mathrm{BCR}=\frac{P W B}{P W C}$

$\mathrm{BCR}=\frac{P W B}{P W C}$

BCR $\geq 1$ Makainvestasilayak

BCR $<1$ Maka Investasi tidak ayak.

Perhitungan NPV, BCR dan IRR dapat dilihat sebagai berikut :

$\begin{array}{ll}\text { NPV Biaya } & =\text { Rp. 326,569,807,764,-- } \\ \text { NPV Manfaat } & =\text { Rp. 1,020,736,802,190,- } \\ \text { NPV } & =\text { NPV Manfaat }- \text { NPV Biaya } \\ \text { NPV } & =\text { Rp. } 694,166,994,426,-\end{array}$

Berdasarkan hasil analisis nilai NPV $=$ Rp. 694,166,994,426,-> 0 (Layak). Maka investasi ini dinyatakan layak.

Untuk penilaian BCR (Benefit Cost Rasio)

$$
\begin{aligned}
& \mathrm{BCR}=\frac{N P V M \text { 1nfaat }}{N P V \text { Biaya }} \\
& \mathbf{B C R}=\quad \frac{\text { Rp. } \mathbf{6 . 7 1 9 . 2 6 1 . 1 3 5 , -}}{\text { Rp. } \mathbf{2 . 6 0 1 . 8 2 9 . 9 5 0 , -}-}=\mathbf{2}, \mathbf{5 8}
\end{aligned}
$$

Nilai BCR yang dihasilkan adalah 2,58 > 1, maka investasi ini dinyatakan layak.

\section{SIMPULAN}

Berdasarkan hasil studi kelayakan finansial pada model pengelolaan sampah di Desa Penebel diperoleh nilai NPV adalah sebesar Rp. 694,166,994,426> 0 dan nilai BCR adalah 2,58 $>1$. Kedua nilai NPV dan BCR lebih besar dari syarat yang ditentukan, sehingga investasi dinyatakan layak NPV >0 dan BCR $>1$. 


\section{DAFTAR PUSTAKA}

Azmiyah, Nur, Rizki Purnaini, M. Indrayadi, 2014. Perencanaan Sistem Pengelolaan Sampah Terpadu di Kawasan Pasar Flamboyan Kota Pontianak. Jurnal Teknologi Lingkungan Lahan Basah Universitas Tanjungpura. Vol.2 No.1.

Badan Pusat Statistik Kabupaten Tabanan, 2019. Laju Pertumbuhan Penduduk Desa Kecamatan Penebel. Badan Pusat Statistik Kabupaten Tabanan Provinsi Bali.

Bank Indonesia, 2016. Suku Bunga Dasar Kredit. Diunduh dari : http://www.bi.go.id/id/perbankan/sukubunga-dasar/Default.aspx diakses 10 Januari 2020.

Kementerian Pekerjaan Umum dan Perumahaan Direktorat Jendral Cipta Karya Direktorat Pengembangan Penyehatan Lingkungan Permukiman. 2016. Petunjuk Teknis TPS 3R Tempat Pengelolaan Sampah $3 R$.

Pemerintah Indonesia. Peraturan Presiden No. 45 Tahun 2011 tentang Rencana Tata Ruang Kawasan Perkotaan Denpasar, Badung, Gianyar dan Tabanan. Sekertariat Negara. Jakarta.

Pemerintah Provinsi Bali. Peraturan Gubernur Provinsi Bali Nomor 47 Tahun 2019 mengenai Pengelolaan Sampah Berbasis Sumber. Biro Hukum dan HAM Setda Provinsi Bali. Bali.

Yansen, I Wayan dan I Made Arnatha, 2012. Analisis Finansial Sistem Pengelolaan Sampah di Wilayah Kecamatan Mengwi Kabupaten Tabanan. Jurnal Ilmiah Teknik Sipil Universitas Udayana. Vol. 16. No.1, Januari 2012. 